\title{
Aggression as risk for delinquency and substance abuse in adolescents
}

\author{
Salman Shahzad ${ }^{1}$, Sajida Yasmin ${ }^{1}$. \\ ${ }^{1}$ Institute of Clinical Psychology, University of Karachi, Pakistan. \\ Correspondence email: shahzad_icp@yahoo.com
}

\begin{abstract}
The objective of this study is to explore the role of aggression (i.e. physical aggression, verbal aggression, anger and hostility) in the development of delinquency and drug abuse in adolescents. Hypotheses were formulated where delinquent adolescents would score high on the variables of physical aggression, verbal aggression, anger and hostility. Adolescents who abuse drugs would score high on the variable of aggression as compared to non-users. Total sample of study comprised of 200 adolescents out of which 101 were juvenile delinquents and 105 were non-delinquents of 12 to 18 year olds (mean age $=15$ years) belonging to a low socio-economic status. The sample (delinquents) of the study was selected from central jail of Karachi and non-delinquents were selected from various public sector schools in Karachi by using random sampling techniques. Descriptive statistics were used to get a precise and better view of the characteristics of sample of the data. Independent sample t-test was used to determine the differences of aggression (physical aggression, verbal aggression, anger and hostility) between juvenile delinquents and non-delinquent (control) groups and between drug-users and non-users. The results show significant differences on variables of aggression between delinquent and non-delinquent adolescents. Delinquents are found to exhibit a high level of aggression as depicted by their mean scores on the aggression questionnaire. When subtypes of aggression are analysed delinquents are found to score high on physical aggression, verbal aggression and hostility. However, no significant difference is found between delinquents and non-delinquents on anger subtype. Similarly, t-test analysis and mean difference suggest that those who use drugs have a high level of aggression than those who do not use drugs. Prospects for future research have also been recommended on the basis of limitations drawn from the study. The role of aggression is well established in this study and a disorganised environment is significant in inculcating aggression among adolescents. Parents of high-risk children must be guided on their role in discouraging anti-social and deviant behaviour among their children. Also, results are useful for teachers who can identify a positive role they can play in teaching, coping skills to high risk children. Moreover, education is found
\end{abstract}


to be a protective factor and thus the government must take initiatives to design and implement large scale life skills training programmes to overcome the problems that adolescents face.

$$
\begin{aligned}
& \text { العدو انية كأحد مخاطر الجنوح و تعاطي المخدرات عند المر اهقين } \\
& \text { سلمان شهز ادو ساجدة ياسمين } \\
& \text { معهد السيكولوجيا السريرية، جامعة كار اتثي، باكستان } \\
& \text { البريد الإلكتروني: shahzad_icp@yahoo.com }
\end{aligned}
$$

الملخص:

هدف هذه الدر اسة هو النظر في دور العدوانية (العدوان الجسدي و اللفضي و الغضب و والفي الفعل العدواني) في

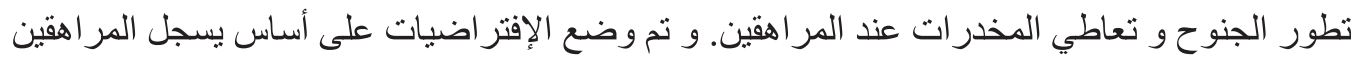

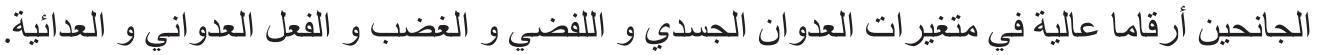

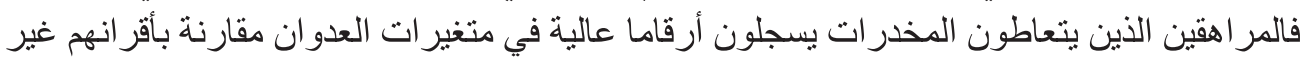

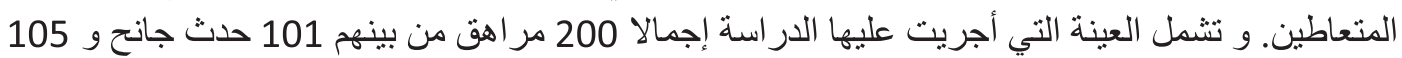

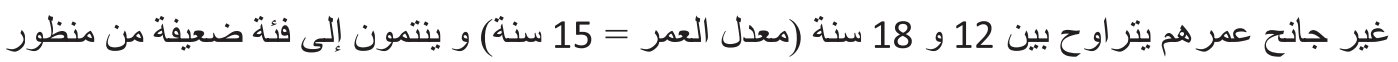

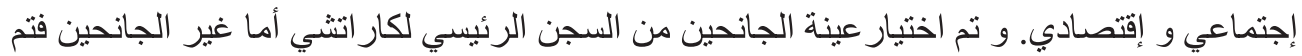

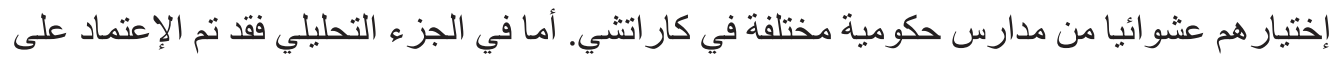

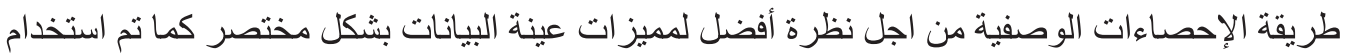

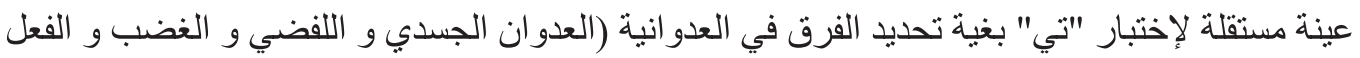

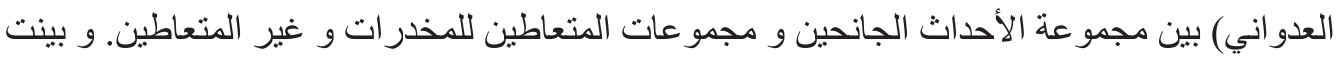

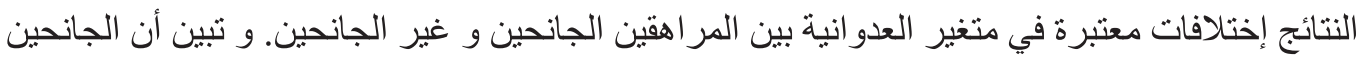

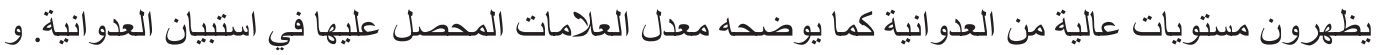

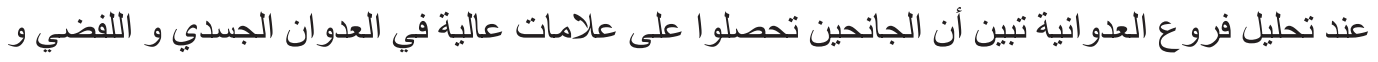

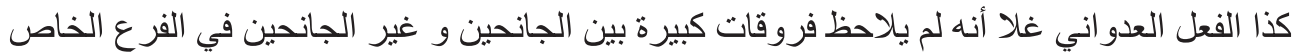

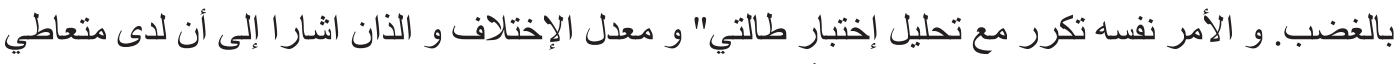

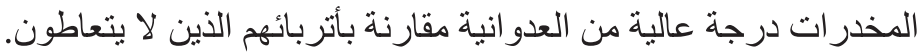

أما بخصوص الآفاق البحثية المستقلية، فقد تم الإشارة إليها من خلال محدودية الدراسة المقترحة، فدور

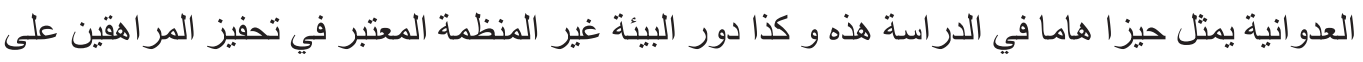

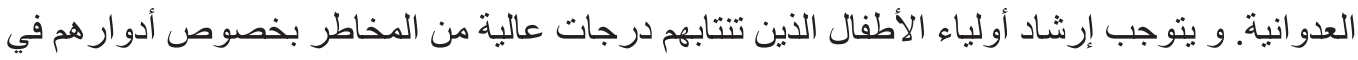

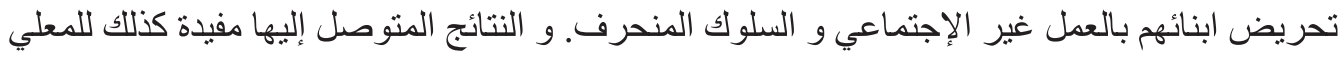

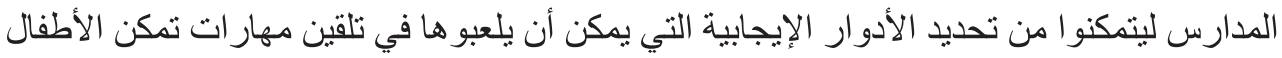

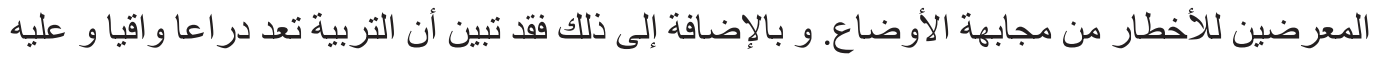

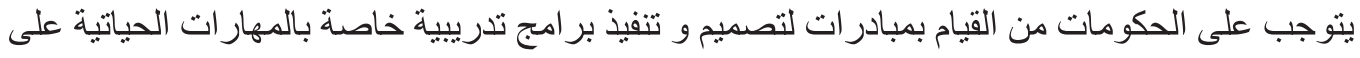
نطاق واسع و ذلك لتجاوز العقبات التي يو اجهها من هم في سن المر الهقة. 
Keywords: Aggression, Delinquency, Substance Abuse, Adolescents

\section{Introduction}

Psychologists and sociologists regard adolescence as a phase of life marked by chaos and distress. During this period of life adolescents are not just prone to high risk anti-social activities but they also experience stress and high levels of negative emotions due to biological changes that occur during puberty. ${ }^{1}$ Various studies have provided evidence that adolescent phase of life is marked by hassles, negative emotions and heightened anguish. ${ }^{2,3}$

Aggression is a term widely used in the literature on problem behaviour, but it is rarely defined and it is often not distinguished from "anti-social behaviour". The word "aggression" covers a multitude of behaviours from open defiance and hostility to covert anti-social acts such as stealing or lying. Lewis defines human "aggression" as "behaviours by one person intended to cause physical pain, damage or destruction to another". ${ }^{4}$ Other writers have expanded the concept to include "instrumental aggression" which is aimed at securing extraneous rewards, not the pain of the victim, while others still have used the term "hostile aggression" to encompass the aim of inflicting injury on others. Bandura makes the point that such distinctions are misleading as most aggression has some other goal than injury to the victim. ${ }^{5}$ He defines "aggression" as "behaviour that results in personal injury and in the destruction of property". The injury may be psychological or physical in nature.

Many researchers have shown evidence for a relationship between early aggression and later delinquent and anti-social behaviours. Studies consistently support the hypothesis that early aggressive behaviour that is measured from ages six to 13 is a strong predictor of violence among males in later life. ${ }^{4,5}$ A study in Orebro, Sweden, found that two-thirds of boys who were rated by teachers as aggressive at the age of 10 and 13 were more likely to engage in offensive behaviour and have criminal records by the age of 26. Their risk to engage in anti-social activities was six times greater than their counterparts who were not rated as aggressive. ${ }^{6}$

Researchers adopt a social learning perspective in proposing a theory of the development of aggression. ${ }^{9,10}$ They argue that anti-social behaviour in young boys is learnt at home. Parenting which is characterised by harsh and inconsistent discipline, lack of supervision of children and little positive parental involvement with the child teaches children to become anti-social. By failing to support pro-social behaviour and punish anti-social behaviour, aggressive behaviour of the child is aggravated. Aggressive child behaviours 
are then hypothesised to lead to rejection by peers and academic failure, both of which reinforce commitment to deviant peer groups and delinquent behaviour.

Delinquent behaviour or other anti-social activity is not the only consequence of high aggression among adolescents. Also, adolescents who have high aggression are prone to indulge in inimical drug use. The term drug abuse is discouraged due to its ambiguous nature. 'Harmful use' and 'hazardous use' are the equivalent terms in WHO usage, although they usually relate only to effects on health and not to social consequences. Thus the definition published in 1969 by the WHO Expert Committee on Drug Dependence was "persistent or sporadic excessive drug use inconsistent with or unrelated to acceptable medical practice". ${ }^{11}$

There is evidence in literature which suggests that those who are aggressive and exhibit violent behaviour at a young age are more likely to succumb to substance abuse. Bukstein asserted that aggression in early life is a risk factor for the subsequent development of drug abuse. ${ }^{12}$ He also suggested that aggression gives an impact on progression of drug abuse because of its direct pharmacological effect or indirectly by its influence on attitude of the individual.

Literature utilising developmental perspective and prospective longitudinal designs for the assessment of potential risk factors for early-onset substance use is scant. Of the few studies that have examined early-onset substance use, findings suggest that parental use of substances and child temperamental characteristics have been identified as important predictors of early-onset substance use. . $^{13,14}$

Aggressive adolescents are likely to engage in drug abuse because they are usually rejected by their peers and thus are more vulnerable to get entrapped in bad company where drug use is encouraged and facilitated. The multistage social learning model asserts that an important factor in escalation of adolescent substance use is peer pressure. ${ }^{15}$ Affiliation with a deviant peer group is also indicative of social skill deficits (e.g. being impolite, uncompromising or indifferent) which makes it difficult for these individuals to engage in healthy social activities. Research has found that one of the strongest predictors of adolescent-onset substance use is association with a substance-using peer group, and most adolescent substance use takes place within a social context. ${ }^{16,17}$

Adolescents, especially delinquents and those who engage in anti-social practices are most despised and are a neglected segment of Pakistani society. They are ostracised and alienated because of their anti-social behaviours 
which as an effect fortify their resentment toward society and increase their likelihood to join delinquent peer groups. This research highlights aggression as an early risk factor for delinquency and drug abuse and thus emphasises appropriate handling of aggressive behaviours of youth if it is to be kept under check.

\section{Methodology}

\section{Participants}

A sample of the present study comprised of 206 male adolescents. They were further divided into two groups (101 delinquents and 105 non-delinquents). The first sample was of those male adolescent delinquents who were accused of delinquency. The second sample comprised of non-delinquent adolescents from several urban public sector high schools located in different areas of Karachi. A requirement for participants in this sample was that they had no history of being accused of delinquency. The age of participants in both samples ranged from 12 to 18 years (Mean age $=15$ years, SD $=1.86$ ). The entire sample comprised of adolescents living in 'two parent' families. This was done to minimise the effects of divorce and separation of parents on the adolescents. The socio-economic status was assessed through national expenditure survey by Federal Bureau of Statistic. ${ }^{18}$

\section{Measures}

\section{Personal information sheet}

It consisted of personal information, family-related and education-related information. Personal information was obtained based on: the age, gender, number of siblings, education, residential area, family structure, family members, family income and the number of income earners. Also the nature of their relationship with parents, siblings and peers was explored via interview. Additional questions were posed to delinquent group participants regarding their past criminal history.

\section{Buss-Perry aggression questionnaire-short version}

Aggressiveness, measured with the Aggression Questionnaire (AQ) was used to measure aggression. ${ }^{19,20}$ This questionnaire consists of 12 Likerttype items rated on a six-point scale. The AQ is divided into four sub scales: Physical Aggression (PA), Verbal Aggression (VA), Anger (ANG) and Hostility (HO). Regarding the AQ-12, researchers report internal reliability es- 
timates from four samples of American (2 samples), British, and Canadian undergraduate students (total $\mathrm{n}=984$ ). ${ }^{20}$ Reliability estimates ranged from .71 to .76 for anger, from .70 to .75 for hostility, from .73 to .83 for verbal aggression, and from .79 to .80 for physical aggression. Because Cronbach's Alpha is sensitive to the number of items included in a given scale, these authors also calculate adjusted Alpha coefficients of .88 to .92 for the four subscales using the Spearman-Brown prophecy formula.

\section{Procedure}

Participants of delinquent groups were between the ages of 12-18 years (Mean age $=16$ years, $\mathrm{SD}=1.25$ ) and were selected from the juvenile jail of the central jail of Karachi, Sindh. Non-delinquent group participants were between age ranges of 12-18 years (Mean age $=14$ years, $\mathrm{SD}=1.64$ ) and were recruited from various urban public sector secondary schools located in low socio-economic areas of Karachi. Participants in the non-delinquent group had no history of criminal or anti-social behaviour. All other characteristics of sample were matched with delinquent group participants. A discussion and a review of the proposal were carried out to assess its feasibility and its intended purposes. Then, the examiner approached the participants to discuss about the objective of the study and to obtain their informed consent to participate in the study. They were briefed about the purpose of the study and were assured of the secrecy of the data and their identity. Before administration of measures, efforts were directed towards establishing a rapport so that the participants will be at ease. Finally, a Personal Information Sheet was filled to obtain background information.

\section{Results}

Results of analysis indicate that delinquents and non-delinquents differ on variables of $\mathrm{PA}(\mathrm{t}=-2.678, \mathrm{df}=204, \mathrm{p}<.05), \mathrm{VA}(\mathrm{t}=-2.436, \mathrm{df}=204, \mathrm{p}<.05)$, and $\mathrm{HO}(\mathrm{t}=-5.490, \mathrm{df}=204, \mathrm{p}<.05)$ where mean difference suggests that delinquent adolescents have high levels of aggression as compared to their non-delinquent counterparts. No significant difference is found between delinquents and non-delinquents on variables of anger $(\mathrm{t}=1.039, \mathrm{df}=204$, $\mathrm{p}>$.05). Moreover, analysis suggest that those who use drugs have a high level of aggression than those who do not use drugs $(t=4.921, d f=202$, $\mathrm{p}<.05)$. 
Table 1. Summary demographics of the entire sample

\begin{tabular}{|c|c|c|c|c|c|c|}
\hline \multirow[t]{2}{*}{ Variables } & \multicolumn{2}{|c|}{ Delinquents } & \multicolumn{2}{|c|}{ Non-delinquents } & \multicolumn{2}{|c|}{ Total sample } \\
\hline & $\mathrm{N}$ & $\%$ & $\mathrm{~N}$ & $\%$ & $\mathrm{~N}$ & $\%$ \\
\hline \multicolumn{7}{|l|}{ Education } \\
\hline Secondary (12-17) & 0 & $0 \%$ & 66 & $62 \%$ & 66 & $32 \%$ \\
\hline Matric (14-18) & 0 & $0 \%$ & 39 & $37 \%$ & 39 & $18.9 \%$ \\
\hline Total & 101 & $49 \%$ & 105 & $51 \%$ & 206 & $50.9 \%$ \\
\hline \multicolumn{7}{|l|}{ Drug use } \\
\hline Yes & 35 & $34.7 \%$ & 004 & $3.8 \%$ & 39 & $18.9 \%$ \\
\hline No & 64 & $63.3 \%$ & 101 & $96.1 \%$ & 165 & $80.0 \%$ \\
\hline Total & 101 & $49 \%$ & 105 & $51 \%$ & 206 & $100 \%$ \\
\hline
\end{tabular}

Table 2. Independent sample t-test for the variable of aggression between drug users and non-users, and between delinquents and non-delinquents

\begin{tabular}{|c|c|c|c|c|c|c|c|}
\hline Variable & Group & n & Mean & SD & df & $\mathbf{t}$ & $\mathbf{p}$ \\
\hline \multirow[t]{2}{*}{ Age } & Delinquents & 101 & 16.45 & 1.254 & & & \\
\hline & Non-delinquents & 105 & 14.14 & 1.647 & & & \\
\hline \multirow{3}{*}{$\begin{array}{l}\text { Physical } \\
\text { Aggression }\end{array}$} & Delinquents & 101 & 8.78 & 4.878 & & & \\
\hline & & & & & 204 & -2.678 & .008 \\
\hline & Non-delinquents & 105 & 7.22 & 3.397 & & & \\
\hline $\begin{array}{l}\text { Verbal Ag- } \\
\text { gression }\end{array}$ & Delinquents & 101 & 8.71 & 4.477 & & & \\
\hline
\end{tabular}




\begin{tabular}{|l|l|l|l|l|l|l|l|}
\hline & & & & & 204 & -2.436 & .016 \\
\hline & Non-delinquents & 105 & 7.41 & 3.103 & & & \\
\hline Anger & Delinquents & 101 & 7.96 & 3.542 & & & \\
\hline & & & & & 204 & 1.039 & .300 \\
\hline & Non-delinquents & 105 & 8.42 & 2.783 & & & \\
\hline & & & & & & & \\
\hline & Delinquents & 101 & 10.44 & 3.686 & & & \\
\hline & & & & & 204 & -5.490 & .000 \\
\hline & Non-delinquents & 105 & 7.92 & 2.841 & & & \\
\hline & & & & & & & \\
\hline Aggression & Drug User & 39 & 41.59 & 14.190 & & & \\
\hline & & & & & 202 & 4.921 & .000 \\
\hline & Non-Drug Users & 165 & 31.63 & 10.607 & & & \\
\hline
\end{tabular}

\section{Discussion}

This study is intended to evaluate the role of aggression in adolescents. These findings are consistent with previous findings which suggest that male delinquents have the highest levels of social and violent aggression, while non-delinquent adolescents have more moderate physical aggression than the delinquent counterparts. ${ }^{21}$ There is also evidence in literature which suggests that aggression precedes delinquency and usually serves as a risk factor for delinquency among adolescents. In one study, physical aggression in the kindergarten was the best and only predictor of the later involvement in property crimes. ${ }^{22}$

It is logical to assume that juveniles who are aggressive are more likely to plunge themselves into aggressive social encounters partly because they have limited cognitive and emotional development and partly because their environment provides them opportunities and encouragement to indulge in hostile social situations. As behaviour is inter-connected with thinking and emotions we can conclude that aggressive behaviour accompanies inadequate cognitive and emotional development.

A study revealed that teens who are mentally immature because of their impoverished environment tend to imitate antisocial behaviour in ways that are normative and adaptive. ${ }^{23}$ Thus delinquent adolescents who are deprived of a salubrious environment and who are raised in crime stricken neighborhoods are more vulnerable to develop aggression in early years of life and ultimately engage in delinquent and anti-social behaviours. 
Furthermore, research reveals that anger is present in equal proportions between delinquent and non-delinquent adolescents. As all participants were from a low socio-economic class, we can expect them to be victims of deprivation and societal prejudice which might have evoked resentment and anger among these adolescents. In Pakistan, social chaos and economic instability has appallingly influenced youth especially those who belong to a low socio-economic status. Research findings are also consistent with this argument and suggest that community deprivation can produce resentment and emanates violence among youths. ${ }^{24}$ Frustration and anger are natural outcomes of uncertainty and insecurity that prevail in Pakistan.

It was also hypothesised that those who use drugs would differ from nondrug users on the variable of aggression. High level of aggression among drug users can be attributed to their excessive drug usage as mental inhibitions are set free under influence of drugs making individuals prone to aggressive behaviour. However, in the present study, researchers have tried to highlight aggression as a risk factor and assert that a high level of aggression among adolescents increases their susceptibility towards drug use. Participants who reported to be drug users were detained in the central jail and were not currently using drugs; this therefore helps to rule out the possibility that their high level of aggression was due to drug influence.

Previous researches also indicate a relationship between early aggression and subsequent drug abuse. Aggressive behaviour was found to be a discriminative factor among boys who were and who were not involved in delinquent activities and substance use within a sample of boys identified as aggressive by their teacher of those between the ages of 10-21 years. ${ }^{25}$ Therefore, we can aver that adolescents who use drugs are generally more aggressive and their aggression shoves them into situations where drug use is facilitated and encouraged.

On the basis of these findings certain recommendations can be made. Firstly, because aggression is a risk factor of delinquency and drug abuse, it must be addressed as early as possible. Detecting risks at early age may help parents, teachers and children themselves to tackle difficulties in their lives. Schoolbased preventive interventions must be designed to screen and treat high risk children. Coping skills and life skills training must be imparted to these high risk children in order to promote their better adjustment in their environment.

Parents and teachers must collaborate to guarantee successful implementation of such preventive interventions. Social unrest and political instability is rampant in Pakistan and has rendered children and adolescents vulnerable. A general awareness regarding drug use and its harmful consequences and early signs and symptoms of drug abuse must be conveyed to families so that 
they can play effective roles in detecting and managing drug abuse problems at an early stage. It is also because education is found to be a mediating factor and can significantly reduce chances of involvement in anti-social activities. Government and social welfare organisations must identify their roles and promote educational facilities in socio-economically backward areas. Awareness regarding importance of education should be spread with a systematic and strategic programme carried out by professionals both at micro and macro levels. When implementing the programmes to overcome such problems faced by young people, it is necessary to implement Evidenced Based Practices (EBPs) in treatment and prevention alike. The EBPs are cost effective in improving the wellbeing and the quality of life.

In conclusion, adolescents who constantly cope with stressful life situations and aggressive surroundings are likely to be aggressive as a coping and therapeutic strategy. They systematically progress toward serious anti-social and delinquent behaviours with progression of opportunities that are offered by their environment. Their aggressive behaviour makes their affiliation with deviant peer groups more probable and thus their probability to indulge in drug abuse and delinquent activities is enhanced.

The present study has limitations which should be considered in future research; Sample 1, ratio of drug users to non-drug users in this sample was not balanced. Findings must be replicated on a large sample of drug users in order to generalise findings. Sample 11, consisted of male adolescents and thus findings could not be generalised on female adolescents. Future researches must evaluate implications of aggression among female adolescents. Also future researches must focus on risk factors other than aggression that can lead to delinquency and drug abuse among adolescents.

\section{References}

1. Gottfredson MR, Hirschi T. A General Theory of Crime. Stanford, California: Stanford University Press: 1990.

2. Agnew R, Brezina T. Relational problems with peers, gender, and delinquency. Youth \& Soc 1997;29:84-111.

Doi: http://dx.doi.org/10.1177/0044118X97029001004

3. Compas BE, Wanger BM. Psychosocial stress during adolescence: Intrapersonal and interpersonal processes. In Colten ME, Gore S. (Eds.), Adolescent stress: Causes and Consequences New York: AldineDeGruyter: 1991;67-92 
4. Lewis DO. Development of the Symptom of Violence, In Lewis M. (Ed.), Child and Adolescent Psychiatry. A Comprehensive Textbook. Baltimore: Williams and Wilkins: 1996; 334-44

5. Bandura A. Aggression. A Social Learning Analysis. Prentice Hall Inc:1973.

6. Loeber R. Developmental continuity, change, and pathways in male juvenile problem behaviors and delinquency. In J.D. Hawkins (Eds.). Delinquency and Crime: Current Theories. Cambridge, UK: Cambridge University Press: 1996;1-27

7. Loeber R, Hay DF. Key issues in the development of aggression and violence from childhood to early adulthood. Ann Rev Psy 1996;48:371410.

Doi: http://dx.doi.org/10.1146/annurev.psych.48.1.371

8. Stattin H, Magnusson D. The role of early aggressive behavior in the frequency, seriousness, and types of later crime. J Consult Clin Psy 1989;57:710-18.

Doi: http://dx.doi.org/10.1037/0022-006X.57.6.710

9. Patterson GR, DeBaryshe BD, Ramsey E. A developmental perspective on antisocial behavior. Am Psy 1989;44:329-35.

Doi: http://dx.doi.org/10.1037/0003-066X.44.2.329

10. Patterson GR, Capaldi D, Bank L.An Early Starter Model for Predicting Delinquency. In Pepler DJ, RubinKH. (Eds.), The Development and Treatment of Childhood Aggression. Hillsdale, NJ: Lawrence Erlbaum Associates: 1991.

11. WHO Expert Committee on Drug Dependence: sixteenth report. Geneva, World HealthOrganization, 1969 (Technical report series 407) available from http://whqlibdoc.who.int/trs/WHO_TRS_407.pdf; accessed 4 February, 2013.

12. Bukstein OG. Aggression, Violence, and Substance Abuse in Adolescents. Adol Subs Abuse and Dual Disorder, 1996;5(1):93-109.20.

13. Costello EJ, Erkanli A, FedermanE, Angold A. Development of psychiatriccomorbidity with substance abuse in adolescents: Effects of timing and sex. J Clin Child Psy 1999;28:298-311.

Doi: http://dx.doi.org/10.1207/S15374424jccp280302 
14. Masse LC, Tremblay RE. Behavior of boys in kindergarten and the onset ofsubstance use during adolescence. Arc Gen Psy 1997;54:6268.

Doi: http://dx.doi.org/10.1001/archpsyc.1997.01830130068014

15. Simons RL, Conger RD, Whitbeck LB. A multistage social learning model of theinfluences of family and peers upon adolescent substance abuse. J Drug Iss 1988;18(3):293-315.

16. Clark DB., Parker AM, Lynch KG. Psychopathology and substance-related problemsduring early adolescence: A survival analysis. J Clin Child Psy 1999;28:333-41.

Doi: http://dx.doi.org/10.1207/S15374424jccp280305

17. Oetting ER., Beauvais F. Common elements in youth drug abuse: Peer clusters and other psychosocial factors. J Drug Iss 1978;2:133-51.

18. Federal Bureau of Statistics. Household Income and Expenditure Survey.Government of Pakistan. In Siddiqui Z. Family functioning and Psychological Problems as Risk Factors in Development of Juvenile Delinquency. Unpublished Doctoral Dissertation, Institute of clinical Psychology, university of Karachi: 2003.

19. Buss AH, Perry MP. The aggression questionnaire. JPerson Soc Psy 1992;63:452-59.

Doi: http://dx.doi.org/10.1037/0022-3514.63.3.452

20. Bryant FB, Smith BD. Refining the architecture of aggression: A measurement model for the Buss-Perry Aggression Questionnaire. J of Res in Person 2001;35(2):138-67.

Doi: http://dx.doi.org/10.1006/jrpe.2000.2302

21. Capuano A. Examining Empathy, Cognitive Distortions, and Social and Physical Aggression in Delinquent and Non-Delinquent Adolescents: 2001.DOI: https://etd.ohiolink.edu/rws_etd/document/get/ bgsu1300742375/inline

22. Haapaslo J, Tremblay RE. Physically aggressive boys from ages 6 to 12. Familybackground, parenting behavior, and prediction of delinquency. JConsult Clin Psy 1994;62:1044-1052.

http://dx.doi.org/10.1037/0022-006X.62.5.1044 
23. Moffitt TE. Adolescence-Limited and Life-Course-Persistent antisocial behavior: A developmental taxonomy. Psyl Rev 1993;100:674701 .

Doi: http://dx.doi.org/10.1037/0033-295X.100.4.674

24. Peeples F, Loeber R. Do individual factors and neighborhood context explain ethnic differences in juvenile delinquency? J Quant Crim 1994; 10:141-58.

Doi: http://dx.doi.org/10.1007/BF02221156

25. O’Donnell, Julie D, David JH, Robert DA. Predicting serious delinquency and substance useamong aggressive boys. J Consult Clin Psy 1995;63(4):529-37.

Doi: http://dx.doi.org/10.1037/0022-006X.63.4.529 